http://dx.doi.org/10.1590/0102-4698125502

\title{
QUAL O LUGAR DOS MATERIAIS VISUAIS NA PESQUISA EM EDUCAÇÃO?
}

\author{
Susana Rangel Vieira da Cunha*
}

RESUMO: Convivemos com os mais diversos materiais compostos por imagens e textos, no entanto, apesar do convívio secular com os materiais visuais e da participação deles em nossas vidas, nosso olhar, na maioria das vezes, não percebe as diferentes funções e combinações que as imagens assumem nesses materiais. Mesmo não sendo um recurso usual no campo da pesquisa educacional mesclar narrativas verbais e visuais, nota-se uma disposição em utilizar materiais visuais nas investigações como possibilidade metodológica e nos modos de narrar e apresentar os artefatos acadêmicos. Este artigo tem a intenção de realizar um levantamento analítico sobre materiais visuais utilizados em estudos com crianças produzidos por uma linha de pesquisa investigou infâncias, educação infantil e crianças no período de 2008 a 2012. Ancorada em que autores que discutem a visualidade na contemporaneidade, a autora examina os materiais visuais que compõem os artefatos acadêmicos e as funções que eles desempenham.

Palavras-Chave: Materiais visuais. Pesquisa educacional. Artefato acadêmico.

\section{WHAT IS THE PLACE OCCUPIED BY VISUAL MATERIALS IN EDUCATION RESEARCH?}

ABSTRACT: We live in contact on a daily basis with a diversity of visual and textual composed material. Despite the secular familiarity we have with visual materials and their expressive presence in our lives, we often overlook the different roles and combinations that these images assume on these materials. While mingling verbal and visual narratives is not a usual resource in the field of Education research, we have noticed a disposition to use visual materials in the investigative process as methodological possibility as well as a technique to narrate and presenting academic artefacts. This paper aims to perform an analytical survey on visual materials employed on children's studies conducted by a research line on childhood, children's education, and children, in the period of 2008 to 2012. Based on authors that discuss visuality in the contemporaneity, this author analyzes the visual materials that comprise the category of academic artefacts and the roles played by them.

Keywords: Visual materials. Research on Education. Academic artefact.

* Doutora em Educação pela Universidade Federal do Rio Grande do Sul (UFRGS). Professora da Graduação e do Programa de Pós-Graduação em Educação da Faculdade de Educação da Universidade Federal do Rio Grande do Sul (UFRGS). Coordenadora do Grupo de Estudos de Educação Infantil e Infância (GEIN). Coordenadora editorial da Coleção Educação e Arte, Editora Mediação. E-mail: rangel.susana@gmail.com 


\section{IMAGEM (NÃO) É CONHECIMENTO}

Analfabetos visuais, cegos, distraídos, admirados ou arrebatados pelo universo visual, temos dificuldades em manufaturar, criar, compor, manusear imagens e expressar pensamentos, emoções, conceitos utilizando a linguagem visual. São inúmeras as causas ${ }^{1}$ para a pouca experiência que temos em utilizar imagens como meio para veicular ideias, mas uma delas é o entendimento de que a forma mais adequada para expressar pensamentos e argumentações teóricas é a palavra, escrita ou falada. Nota-se que há uma hierarquização entre as duas linguagens: a escrita porta o "conhecimento, o saber e a verdade", e as imagens, muitas vezes, servem para expressar sentimentos e, quando muito, como "prova" de um acontecimento, um registro que "ilustra", "comprova" e enaltece a veracidade do que é escrito.

A respeito de como são consideradas as duas formas de expressão, Mirzoeff (1999, p. 24) afirma que "[...] a cultura ocidental tem privilegiado o mundo verbal de forma sistemática, considerando-o a mais alta forma de prática intelectual e qualificando as representações visuais como ilustrações de ideias de segunda ordem" (tradução da autora). No entanto, as produções artísticas até o início do século XIX foram também produtoras de mundos, instituidoras de determinadas realidades, demarcadoras dos grupos sociais, formuladoras dos corpos, (in)visibilizadoras das terras e povos conquistados. $\mathrm{E}$, se nas últimas décadas do século $\mathrm{XX}$, houve a intensificação na produção e circulação de imagens, é porque somos uma civilização que há milênios cultua e acredita no poder de verdade das imagens (CUNHA, 2005).

As imagens contemporâneas, assim como foi a produção de arte, cada vez mais produzem nossas relações, concepções e conhecimentos no e sobre o mundo. Evidentemente, hoje a circulação e o acesso que temos, os modos interpretativos e interativos que estabelecemos com elas, são completamente diferentes das épocas anteriores. Mudaram os suportes, as tecnologias, as formas de visualização e o modo de nos posicionarmos em relação às imagens; porém, as pedagogias visuais formulam conhecimentos.

O recurso de combinar texto e imagem é recorrente na história ocidental. Observa-se essa junção nas iluminuras dos manuscritos medievais, na via-crúcis das igrejas católicas, nos alfabetos egípcios, em mapas, cartas topográficas e de navegação, nas enciclopédias e nos dicionários, entre outros materiais que aliaram as duas linguagens com o intuito de aprimorar o entendimento sobre o mundo, formular e comunicar ideias, instituir pontos de vista. 
É interessante observar que ao mesmo tempo em que a arte começou a se desprender das representações realistas, cubistas e dadaístas, no início do século XX, começaram a combinar imagens, palavras e textos, incorporando em suas obras fragmentos de jornais e de materiais escritos do cotidiano. Também nesse mesmo período os franceses Jules Chéret, Alphonse Mucha e Toulouse-Lautrec criaram o cartaz publicitário, mesclando imagens e informações escritas. Pode-se dizer que os afiches franceses e os experimentos cubistas e dadaístas, como o livro visual Une semaine de bonté, do artista Marx Ernst, foram os precursores dessa linguagem híbrida explorada mais adiante na produção artística e publicitária. Posteriormente, a partir dos anos 50, a Pop Art recuperou em suas composições a linguagem miscigenada e explorou exaustivamente essa combinação, assim como a literatura infantil, a publicidade, as revistas e os jornais.

Atualmente, convivemos com os mais diversos materiais compostos por imagens e textos. É uma marca dos produtos contemporâneos a composição imagética e escrita. Embalagens, revistas, jornais, livros, folders, manuais, propagandas, celulares, cardápios, ecografias, calendários, placas de trânsito, mapas, jogos eletrônicos, produções artísticas, cédulas de dinheiro, carros, aviões, trens, ônibus, grafites, pichações, sites, banners, redes sociais, entre tantos outros artefatos, são apresentados por meio dessas modalidades expressivas distintas, mas que, articuladas, e conforme sua organização, composição, diagramação, ênfase, tamanho, produzem uma retórica verbo-visual no suporte que a veicula.

As imagens formulam mundos, instituem práticas culturais, mas ainda acreditamos que a palavra é a fonte de saberes. Na publicidade, por exemplo, palavras e imagens formulam narrativas de convencimento para que algo seja desejado por nós. Nos jornais impressos e virtuais, as fotografias na maioria das vezes amplificam de tal modo o texto que passam a ser formuladoras dos acontecimentos. Para Sontag (2007, p. 141), "as fotos têm deixado as marcas de como os conflitos importantes são julgados e lembrados. O museu da memória ocidental é hoje, sobretudo, visual". Os acontecimentos são impressos em nossa memória pelas imagens que por sua vez ultrapassam o caráter informativo, ilustrativo, assumindo funções de produzir realidades. $\mathrm{Na}$ fotografia ${ }^{2}$ dramática de Paul Hansen, por exemplo, onde são mostradas, em primeiro plano, duas crianças pequenas mortas carregadas nos braços por um grupo de homens palestinos, aparece abaixo da imagem o texto descrevendo parcialmente o que vemos. Porém, “o 'traduzir' 
pictórico das palavras é, aqui, impossível” (BARTHES, 1990, p. 54), pois nesse caso a imagem tem uma autonomia em relação ao texto no sentido de produzir uma narrativa maior do que a escrita nos dá. A imagem, além de ultrapassar as informações do texto, é uma metáfora do infanticídio em Gaza. Não são apenas as duas crianças fotografadas que vemos, mas centenas de outras que vivem situações de risco, violência, fome, abandono.

Hernández (2007) afirma que vivemos em um período de "analfabetismo visual", em que nossa capacidade de examinar, entender e criticar os "textos" visuais, bem como de elaborar e criar narrativas visuais, é muito reduzida. Para o autor, é necessário aprendermos a utilizar as imagens para expressarmos nossas concepções da mesma forma que utilizamos as palavras. Mesmo cercados por imagens, temos pouco entendimento em relação às pedagogias visuais, discernimento dos diferentes posicionamentos que as imagens assumem, bem como reduzida habilidade para criação de outras imagens e narrativas com elas.

Aprende-se desde muito cedo a privilegiar a palavra em detrimento da imagem quando adultos escrevem ao lado dos rabiscos das crianças pequenas o nome do suposto "objeto-coisaanimal-pessoa" desenhado, mesmo que a criança não tenha intenção de elaborar uma forma reconhecível. O adulto ao escrever, de certa forma, está dizendo: o desenho precisa da palavra para ser entendido. De forma semelhante, nos artefatos acadêmicos - relatórios de estágio, pesquisa, monografias, TCCs, dissertações e teses - a imagem, em geral a fotografia, quando utilizada, é descrita nas legendas e/ou "explicada" no corpo do texto.

Nos artefatos acadêmicos no campo da Educação ${ }^{3}$, raramente as imagens têm o papel de formular conhecimentos. Sua função mais usual é de registro ou de confirmar aquilo que foi expresso verbalmente. No entanto, na última década surgiram trabalhos investigativos em Educação (MÜLLER, 2007; DIEFENTHÄLER, 2009, BECKER, 2009; PETRY, 2009; HORN, 2010; ABREU, 2010; RAMOS, 2011; FERREIRA, 2012; TROIS, 2012) que ousam utilizar as imagens para criar metodologias, considerá-las dados e outra possibilidade discursiva nos artefatos acadêmicos.

Este artigo tem como objetivo examinar dissertações e teses que utilizaram materiais visuais como metodologia de pesquisa e/ ou nos artefatos acadêmicos. O levantamento tem como referência as investigações produzidas em um programa de pós-graduação em Educação entre 2008-2012, em uma linha de pesquisa que 
objetiva examinar as infâncias e sua educação na multiplicidade e heterogeneidade de espaços e contextos. As investigações selecionadas foram aquelas realizadas com crianças, a maioria em contextos escolares, em trabalhos nos quais as autoras buscaram "criar" metodologias de pesquisa utilizando materiais visuais e/ou utilizaram os materiais visuais como coprodutores das narrativas nos artefatos acadêmicos, não apenas como "figuras" que ilustram os textos, mas como produções discursivas. Assim, as análises se atêm a dois aspectos: como as pesquisadoras lançaram mão dos materiais visuais para produzir suas pesquisas e como eles foram apresentados nos artefatos acadêmicos.

\section{MATERIAIS VISUAIS NA PESQUISA COM CRIANC̣AS}

No Brasil, nas últimas duas décadas, as pesquisas educacionais ${ }^{4}$, de um modo geral, talvez por influência da Etnografia, Antropologia Visual, dos Estudos Culturais, Midiáticos, de Gênero e da Cultura Visual, Semiótica e mais recentemente a Pesquisa Baseada nas Artes (EISNER, 1998; HERNÀNDEZ, 2008) e a A/r/tografia (IRWIN, 2008; DIAS, 2006, 2009), têm se valido de materiais visuais em vários momentos das investigações. Solange Jobim e Souza, Rita Ribes Pereira e Sonia Kramer, na metade da década passada, questionavam e problematizavam a utilização das imagens, em especial as fotográficas, como recurso metodológico nas pesquisas em Educação com crianças. Hoje, é considerável o número de trabalhos acadêmicos em Educação, principalmente na Sociologia da Infância, que utiliza imagens, em especial as fotográficas, como metodologia de pesquisa e como forma de visibilizar as pesquisas. Estamos em um estágio em que existe produção de pesquisas com imagens e análises sobre elas, no entanto, são raros os trabalhos que analisam como as imagens estão sendo utilizadas nos artefatos acadêmicos.

Em geral, a pesquisa com crianças utiliza registros fotográficos ${ }^{5} \mathrm{e} / \mathrm{ou}$ em vídeo, em que a fotografia tem papel de auxiliar as pesquisadoras a "verem" o que não foi possível ser visto em campo, servindo também para mostrar os acontecimentos das pesquisas. Essa tentativa de buscar imagens que mostrem de forma mais fidedigna os acontecimentos pode nos levar a priorizar a "presença" do que vemos e não as ausências. Aliada ao registro da presença, "a fotografia é um regime discursivo que nos predispõe a aceitar que a imagem fotográfica é fielmente real" (FISCHMAN, 2006, p. 83). Assim, a "realidade" reapresentada e visibilizada nos 
artefatos acadêmicos passa a instituir conhecimentos e visões sobre crianças, infâncias, seus modos de ser e viver.

Para Pereira (2009, p. 260), os pesquisadores também estão imersos na cultura das imagens e nas tecnologias que a produzem, para a autora, o pesquisador "toma de empréstimo seus signos e reorganiza, com isso, seus próprios códigos de apreensão e compreensão dos fenômenos. Não há dúvidas de que com a ajuda dos aparelhos o pesquisador experimenta perspectivas de visada que, sem eles, jamais teria". Muitas vezes, observa-se abundância de registros imagéticos nas pesquisas; no entanto, eles são utilizados, em sua maioria, da captura à apresentação, como significantes e não como possibilidade de produzir significações. Fachadas de escolas, salas, pátios, brinquedos, crianças sentadas em suas mesas são cenas comuns nas pesquisas em Educação. No entanto, elas pouco nos dizem sobre aqueles lugares, aqueles sujeitos e aquele fotógrafo-pesquisador. Segundo categorização de Wolf (2005, p. 38), são imagens transparentes, imagens em que "não vemos a imagem, só a própria coisa representada".

No filme Pro dia nascer feliz, João Jardim coloca como pano de fundo os detalhes dos ambientes escolares: o corrimão descascado, a parede manchada, as cadeiras desordenadamente empilhadas, janelas quebradas. Nesses detalhes, que aparentemente não têm importância na cena, construímos nossas percepções sobre a instituição escolar pública brasileira, não sendo mais aquela escola do filme, mas "as escolas". Seriam as imagens opacas, que possibilitam outras leituras além do representado nelas. $\mathrm{Na}$ pesquisa em Educação, estaríamos utilizando imagens transparentes ou opacas? Nossas imagens possibilitam aos leitores irem além das fachadas (aqui no sentido figurado)? É possível que eles ultrapassem a superfície das "realidades" capturadas?

Os trabalhos aqui examinados, mencionados anteriormente, são as dissertações e teses produzidas em um período de quatro anos em uma linha de pesquisa em Educação. Nesse período foram produzidas oito teses e 27 dissertações, orientadas por quatro professores de diferentes abordagens teóricas. Os critérios para selecionar os trabalhos foram as investigações com crianças nas quais as pesquisadoras se valeram dos materiais visuais na produção da pesquisa e/ou na constituição do artefato acadêmico, bem como aquelas investigações que fizeram uso de referencial teórico para sustentar a utilização das imagens nas pesquisas. Dos 35 trabalhos, 20 utilizaram e apresentaram materiais visuais, sendo que 12 (dez dissertações e duas teses) evidenciaram 
uma utilização diferenciada dos materiais visuais na produção das pesquisas, como metodologia, e experimentaram soluções autorais na apresentação do artefato acadêmico.

Considero elevado o número de trabalhos que utilizaram materiais visuais, tendo em vista que foram produzidos em um programa de pós-graduação em Educação, onde há poucas disciplinas sobre metodologias de pesquisa com materiais visuais. $\mathrm{O}$ fato de um elevado número de trabalhos criar metodologias e narrar as pesquisas com materiais visuais talvez tenha relação com as diversas abordagens teóricas - Sociologia da Infância, Estudos Visuais, Culturais, Foucaultianos, Semióticos e da Arte - que constituem a referida linha, tornando-a híbrida de referências. Nessas abordagens, muitas vezes os materiais visuais têm relevância na criação de instrumentos metodológicos, na produção de registros, nas análises e nos artefatos acadêmicos.

Para empreender as análises, foram lidos os 12 trabalhos, com especial atenção às seções metodológicas e referências bibliográficas, sendo também examinado o modo como as imagens se apresentam nos artefatos acadêmicos. Depois de lidos e (re)vistos, os trabalhos foram agrupados por semelhanças metodológicas e pelas formas de apresentação. Assim, dois focos foram eleitos: o primeiro é sobre como os materiais visuais foram utilizados e produzidos no desenvolvimento da pesquisa; o segundo centrou-se no artefato acadêmico e nos materiais visuais que o compõem.

Para examinar como os materiais visuais foram utilizados nos artefatos acadêmicos, buscaram-se as contribuições de Barthes (1990), Rose (2001), Virilio (2002), Sontag (2007), Wolf (2005) e Rancière (2012) sobre as funções das imagens e as relações entre texto/imagem. Junto com esses autores, somam-se as categorias elaboradas por Domènecch (2001) sobre as imagens que serviram para agrupar por semelhanças os modos pelos quais as pesquisadoras utilizaram as imagens nos artefatos acadêmicos. Depois de muito manusear o material empírico e de dialogar com os referidos autores, foram reinventadas outras "categorias": imagem-exemplo, aquelas que têm a intenção de visibilizar, exemplificar e/ou comprovar os acontecimentos da pesquisa, sendo acompanhadas de textos descritivos e/ou legendas; imagem-poética, que também são registros da pesquisa, mas não têm a intenção de transcrever os acontecimentos, não são acompanhadas de explicações textuais e produzem outra narrativa que a escrita não consegue expressar; imagem-convocatória, relacionada ou não com o texto, seria aquela que Virilio (2002, p. 31) categoriza 
como imagem fática, que força o olhar e prende a atenção; imagemdeslizante é aquela que se desprende do texto escrito e dos registros da pesquisa, às vezes sendo composta por diferentes materiais visuais e possibilitando recriar visualmente outros conceitos. A intenção, ao estabelecer essas "categorias", foi elaborar um esboço analítico para entender as funções das imagens e como estamos nos valendo dos materiais visuais naquilo que será visibilizado aos diferentes públicos.

\section{FOTOGRAFIA ALÉM DO REGISTRO}

$\mathrm{Na}$ pesquisa em Educação, um recurso recorrente é registrar e apresentar por meio da fotografia os acontecimentos da pesquisa. Assim, não seria uma surpresa constatar que nos 12 trabalhos a fotografia está presente. Dos materiais visuais, a fotografia e o vídeo são os meios que conferem às cenas apresentadas o estatuto de verossimilhança.

Nas pesquisas examinadas, a utilização das fotografias foi variada no que diz respeito tanto às formas como foram produzidas quanto aos modos de visibilizá-las no artefato acadêmico. A imagem fotográfica na maioria dos trabalhos assumiu diferentes funções: documentar os diferentes episódios da pesquisa de campo, utilizá-la para entender com maior profundidade e narrar visualmente, às vezes de forma poética, o visto e o vivido na pesquisa. A modalidade mais usual foi como registro das cenas da pesquisa mostrando crianças, espaços escolares, materiais presentes nas escolas, entre outros.

Em geral, a captura da imagem fotográfica se deu nos acontecimentos, sem haver uma elaboração estética pré-definida e muitas vezes em condições adversas, como a pouca luminosidade do ambiente, movimentação rápida das crianças, cenas acontecendo simultaneamente, entre outros acontecimentos. Uma das pesquisadoras explica as dificuldades da obtenção das fotografias quando está em campo:

\footnotetext{
Como o objetivo era capturar o maior número de interações possíveis, a qualidade das fotografias e das filmagens, muitas vezes, ficou comprometida, até mesmo porque, em alguns momentos, enquanto filmava um episódio, também atendia a uma ou outra demanda que surgia diante de mim e que necessitava de intervenção imediata. Além, é claro, das inúmeras vezes que vinham até mim e esbarravam na câmera ou solicitavam atenção. (GUIMARÃES, 2011, p. 119-120)
}

Precisamos dar existência e consistência aos episódios da pesquisa, porém, eles sempre serão versões do registrado. Mesmo que as pesquisadoras pretendessem dar a ver um "real", esse "real" foi a versão fragmentada da pesquisadora-fotógrafa, ou seja, o instante 
capturado e mostrado ao leitor é sempre uma "interpretação" do vivenciado. Outra pesquisadora, que não estava interessada em registros objetivos, mas sim em registrar suas impressões, explica seu processo de captura das imagens: "As fotografias, portanto, foram produzidas e escolhidas através de um vagar, com o duplo sentido da palavra, de demora e de passeio, não eram mais apenas um reflexo daquilo que eu olhava ou prova do que ali acontecia, e sim uma interpretação" (PETRY, 2009, p. 123).

Ao compor os artefatos acadêmicos, posteriormente, notase que a maioria das pesquisadoras se preocupou em retrabalhar as fotografias, recompondo-as, combinando-as umas com outras e também com outros materiais. Muitas composições imagéticas e narrativas não obedeceram à sequência cronológica dos acontecimentos, sendo reorganizadas com o intuito de dar outro sentido ao visto. Também é perceptível o cuidado com a diagramação e em como as fotografias poderiam dialogar com o texto; assim, entre a captura do acontecimento e a sua visibilização no artefato, houve interpretação e recriação.

Em muitas pesquisas, além de expor os acontecimentos, a fotografia foi utilizada como "anotações visuais", um recurso metodológico "para capturar as nuances daquilo que não nos é visível a olho nu" (PEREIRA, 2011, p. 16) e pensar as infâncias (TROIS, 2012) sobre o processo de obtenção das fotografias, a pesquisadora relata:

\footnotetext{
Fui estabelecendo pontos-âncora de observação, como afirma Achutti (2004), que permitiram utilizar a fotografia como instrumento de pesquisa e como forma de narração. Constituí um banco de imagens que dialogava com os textos e com meus rabiscos do campo. O instante de ver era também o instante de pensar. Fotografar é dar a ver, é, também, uma forma de pensar e olhar o real. A busca por encontrar diferentes ângulos de visão, de escolher os enquadramentos ancorava-se na concepção do autor de "dar à imagem um verdadeiro estatuto, outro que ilustrativo". Toda fotografia é um olhar sobre o mundo, levado pela intencionalidade de uma pessoa procurando dar significado a este mundo. (TROIS, 2012, p. 37)
}

Ambas as pesquisadoras utilizaram as fotografias para ampliar as impressões que haviam sido apreendidas em campo. Outra pesquisa que se debruçou sobre as vivências dos bebês nos diferentes espaços da escola infantil utilizou a fotografia e o vídeo para entrecruzar com as anotações do diário de campo (GOBBATTO, 2011). De forma semelhante, o estudo dedicado às interações dos bebês e das crianças bem pequenas com os livros recorreu à fotografia e ao vídeo como principal modo de registro. Porém, 
ao "recontar" em forma de narrativa visual os acontecimentos, a pesquisadora não seguiu "o tempo cronológico das imagens capturadas” (GUIMARĂES, 2011, p. 120). Segundo a pesquisadora:

[...] vejo a fotografia, produzida no contexto do campo da pesquisa, como uma potente linguagem, como elemento que tem a faculdade de narrar os fatos observados e enquadrados, os quais contribuíram para que o "olhar", após o campo, tornasse possível interpretar e expressar aquilo com que os bebês e as crianças bem pequenas interagem, cujas palavras não dão conta de dizer ou dizer melhor. (GUIMARÃES, p. 121)

Em uma investigação sobre as práticas de embelezamento corporal das meninas Kaingang, a pesquisadora utilizou a fotografia como forma de registro, sendo mostrados muitos detalhes nas formas de embelezamento praticadas pelas meninas. Porém, os rostos das crianças não foram identificados, fator que afetou a intenção da pesquisadora em mostrar as apropriações culturais desse grupo. Posteriormente, no artefato acadêmico, muitas fotografias foram compostas com outros materiais visuais, criando uma narrativa sobre as práticas de embelezamento (BRUM, 2011).

Em outra investigação, que teve como pergunta norteadora "Como se desenvolvem, se produzem, se criam modos de vida na escola de educação infantil?”, a pesquisadora utilizou diferentes enquadramentos e cortes nas fotografias, detalhes que geralmente não são registrados, como a posição dos pés das crianças nas cadeiras, o olhar para uma massinha de modelar seguida de fotografias apenas das produções tridimensionais da criança. Para uma mesma cena foram utilizadas várias sequências em que é possível acompanhar os percursos da pesquisadora e as minúcias das ações infantis. Segundo a pesquisadora:

A fotografia acabou tornando-se a própria pesquisa em alguns momentos e não somente um instrumento de retomada, uma prova ou documento do percurso e do processo de elaboração da pesquisa e da dissertação. Acabou colocando-se no trabalho como uma maneira de ver e de pensar o mundo, uma possibilidade de produção das ideias, produção de sentido, produção de mundo [...]. (PETRY, 2009, p. 123)

Em outra investigação, a fotografia e o fotografar das crianças - objeto e ação - foi o material empírico da investigação. Segundo a pesquisadora: "O fotografar como a ação de fazer fotos é o centro deste estudo. Proponho o estudo do fotografar na escola [especial] como um modo de ver, dizer, sentir e relacionar-se produzindo conhecimentos e sentidos" (FERREIRA, 2012, p. 3). Para ela, "as imagens que compõem esta escrita não são ilustração, têm algo a 
dizer, fazem parte da história deste pesquisar [...]. Os textos visuais e escritos desenvolvem/registram este estudo, compõem a sua história" (FERREIRA, 2012, p. 21).

$\mathrm{Na}$ pesquisa Bruxas, bruxos, fadas, princesas, principes e outros bichos esquisitos... as apropriaçoes infantis do belo e feio nas mediações culturais, os registros em vídeo, além de auxiliar na documentação da pesquisa, tiveram o papel de retomar, junto com as crianças, os acontecimentos da pesquisa. "Assim, o audiovisual entrou como gerador de dados, colaborando para esta investigação. Nos registros audiovisuais, foi possível verificar algumas imagens que indicassem uma narrativa que foi construída ao longo deste processo investigativo" (ABREU, 2010, p.101).

Em todas as investigações, as pesquisadoras buscaram referenciais teóricos e justificativas para a utilização das imagens na captura, metodologia da pesquisa, análises de dados e elaboração do artefato acadêmico. Algumas pesquisadoras, além de estabelecer diálogos com a Antropologia Visual, Fotoetnografia e Estudos da Cultura Visual, procuraram referências estéticas em obras de fotógrafos e artistas visuais. Ou seja, para trabalhar com as imagens, não bastaram os suportes teóricos, havendo também a necessidade de uma ampliação de repertórios visuais das pesquisadoras.

\section{OUTROS MATERIAIS VISUAIS NA PRODUC̣ÃO DA PESQUISA}

Além da fotografia, outros materiais visuais foram utilizados como instrumentos metodológicos, entre eles: desenhos, pinturas, colagens, bonecos/as, maquetes, reproduções artísticas, peças artesanais, filmes, cartazes, livros imagéticos, histórias em quadrinho, propagandas. Algumas vezes, as pesquisadoras produziram e disponibilizaram às crianças os materiais com o intuito de desencadear as conversações, outras vezes foram propostas situações lúdico-expressivas em que as crianças produziram materiais visuais e expressaram seus pontos de vista por meio das linguagens visuais.

Assim como a fotografia, a utilização dos materiais foi diversificada. Acredita-se que, para entender, pelo menos um pouco, os modos como as crianças pensam, imaginam e expressam o mundo, devemos desenvolver materiais e outros recursos metodológicos que não estejam centrados apenas na linguagem verbal escrita e falada. Mesmo sabendo que sairiam da zona de conforto proporcionada pelas metodologias de pesquisa com que estavam familiarizadas, muitas pesquisadoras elegeram materiais visuais como disparadores das ações 
da pesquisa e incentivaram as crianças a manifestarem suas ideias por meio deles porque acreditavam que, durante o processo de pesquisa, em torno de 8-12 meses, as crianças teriam oportunidade de ampliar seus repertórios visuais, questionar os significados das imagens, compartilhar com seus pares suas concepções visuais e produzir suas próprias imagens por meio da fotografia, vídeos, desenhos, pinturas, construções tridimensionais, entre outras modalidades expressivas.

Em algumas investigações, os materiais visuais foram os principais instrumentos metodológicos. Como existem poucos estudos sobre a utilização de outros materiais visuais além da fotografia na pesquisa com crianças, as investigadoras, na medida em que desenvolviam a pesquisa, elaboravam os materiais nas interlocuções com as crianças. Para Castro (2008, p. 31): "Neste sentido, pesquisar é fazer: produzir sentidos específicos para aquela situação tal como se desenvolve nos cenários em que o pesquisador se relaciona com aquelas crianças à sua frente".

As pesquisadoras (MORAIS, 2008; DIEFENTHÄLER, 2009; HORN, 2010; ABREU, 2010; FEITOSA, 2011) realizaram propostas metodológicas centradas em materiais visuais e equipamentos para produzir imagens. Máquinas fotográficas, filmadoras, vídeos, materiais gráfico-pictóricos, tecidos, sucatas, reproduções de propagandas e obras de arte, bonecos/as foram disponibilizados às crianças para que elas se valessem deles para se expressar nas diferentes linguagens visuais. Ao se apropriarem dos materiais e equipamentos, as crianças manifestaram seus pontos de vista de forma singular, reapresentaram suas experiências e relações com o mundo e também foram coprodutoras dos dados. A intenção das pesquisadoras foi priorizar os enunciados poéticos na sua fatura e na análise dos dados.

Em uma pesquisa mediada em que a pesquisadora buscou entender como as crianças pequenas rompem com os estereótipos do desenho, foram elaborados Ações Propositoras e Materiais Provocadores (DIEFENTHÄLER, 2009), expressões utilizadas para se referir aos recursos metodológicos criados no decorrer da pesquisa. Para desenvolver as ações da pesquisa, a autora se valeu dos conceitos de bricolagem, de Kincheloe (2004), e de mediação cultural de Martins (2007):

[...] a tarefa de criar os caminhos investigativos a serem desenvolvidos durante a pesquisa foi algo que exigiu escolhas difíceis. Durante o percurso depareime com questões que me faziam adotar de tempos em tempos posturas pesquisativas diferenciadas. Dentre encaminhamentos metodológicos, a bricolagem foi utilizada por possibilitar a utilização de vários instrumentos investigativos em uma mesma pesquisa. 
[...] Martins o utiliza [conceito de mediação] na relação entre público e obra, sendo que me aproprio deste conceito para estabelecer uma relação entre as crianças da pesquisa, suas produções visuais e as imagens utilizadas. (DIEFENTHÄLER, 2009, p. 76-77)

Os materiais provocadores, todos compostos por imagens, foram elaborados após as observações participativas e de algumas constatações da pesquisadora em relação a como os imaginários infantis e suas formas de expressão estão sendo abastecidos pela cultura visual. Segundo ela: "O objetivo principal era o de produzir alguns materiais que viessem ao encontro de inquietações que me acompanharam, no caso, a proliferação de imagens padronizadas nas produções expressivas infantis" (DIEFENTHÄLER, 2009, p. 83).

Um conjunto de propostas - cartas desenhadas enviadas pelo correio, autorretratos desenhados e pintados, desenhos de como imaginam as outras crianças, fotografias em formato de cartão-postal dos locais interessantes de suas comunidades, gravação de vídeos dos locais preferidos das crianças - foi o meio que a investigadora criou para compreender as visões que as crianças "urbanas" e "rurais" produzem sobre si e sobre os outros. Conforme a pesquisadora:

\footnotetext{
Uma das minhas escolhas iniciais foi eleger os modos de expressão das crianças, aqui entendidos como: falas, escritas, desenhos, produção de áudio-visual, e têlas como produtoras e interlocutoras na pesquisa. Assim, as produções verbais e visuais das crianças, as formas delas se expressarem, falarem, narrarem sobre si e sobre os outros através de outras linguagens, foram as referências principais dessa investigação, onde busquei entender as visões e versões de rural e urbano a partir dos olhares e modos de expressão das crianças. (HORN, 2010, p. 59)
}

A proposta de intercambiar os materiais visuais entre as crianças foi influenciada pela "pedagogia da interculturalidade" proposta por Sarmento (2007) e pelas pesquisas que o referido autor desenvolveu com os pesquisadores da UFSC. Assim, a pesquisa "envolveu a ação das crianças, sua relação com o outro, com o 'desconhecido', com seus universos, suas formas de brincar, de viver, o diálogo com suas escritas e desenhos, com suas formas de narrar suas vivências" (HORN, 2010, p. 68).

Ao lançar as propostas às crianças de diferentes contextos culturais, a investigadora disponibilizava os equipamentos e materiais e cercava as crianças de questionamentos. Nos desenhos, por exemplo, em que foi proposto que elas desenhassem como imaginavam as crianças do outro grupo cultural, ela perguntava: "Como imaginar alguém que não conheço? Do que será que gosta, brinca, faz, como será que é o(a) meu amigo(a) secreto(a)?" (HORN, 2010, p. 75). 
Posteriormente, nas análises, os materiais visuais produzidos pelas crianças foram centrais para entender as concepções que as crianças têm sobre as crianças rurais e urbanas.

Semelhante às metodologias de Horn e Diefenthäler, a pesquisa Bruxas, bruxos, fadas, princesas, príncipes e outros bichos esquisitos... as apropriacõos infantis do belo e feio nas mediacooes culturais também se valeu de um percurso metodológico baseado em diferentes propostas, cujo objetivo foi incentivar variadas formas de expressão das crianças e ampliar seus repertórios culturais. O interesse principal da investigação foi entender, e problematizar, como as crianças produziam suas concepções sobre o belo e o feio e como elas construíam visualmente suas concepções. Para entender as formulações infantis, a investigadora trabalhou em dois focos: propostas expressivas e propostas para ampliação de repertórios visuais. As crianças, durante o processo da pesquisa, tiveram oportunidade de experimentar várias possibilidades da linguagem visual e criaram a história "Cabruxa, a Bruxa Inventada", que foi um dos meios pelos quais a pesquisadora buscou entender como as crianças elaboravam suas noções de belo e de feio. Segundo a pesquisadora: "Meu papel como professora/ pesquisadora foi provocar situações para que as crianças refletissem sobre suas concepções de belo e feio e em que medida minhas intervenções problematizaram e questionaram as naturalizações destas concepções” (ABREU, 2010, p. 14).

Em outra pesquisa que problematizou bonecos/as e as práticas do brincar, a pesquisadora, depois de uma vasta pesquisa sobre bonecos e bonecas, disponibilizou às crianças bonecos/as que usualmente a maioria das crianças não tem acesso. Com bonecos amputados, negros, gordos, com cabelos encarapinhados e escuros, míopes com óculos, entre outras características físicas, misturados com os bonecos/as da escola, a pesquisadora buscou entender como as crianças operam com os conceitos de corpo, raça e gênero em suas brincadeiras. "Optei por ouvir as crianças e o que elas tinham a dizer. Contar sobre bonecos e bonecas com os quais brincavam e observavam nessa pesquisa" (MORAIS, 2008, p. 51).

$\mathrm{Na}$ investigação cuja temática foi "as infâncias da guerra" (FEITOSA, 2011), desenvolvida com crianças que vivem em um abrigo institucional, o pesquisador ofereceu máquinas fotográficas para que as crianças mostrassem seus pontos de vista sobre o local em que viviam. Para entender suas expectativas de vida, foi proposta a construção de maquetes em caixas de sapatos, quando as crianças tiveram a oportunidade de "mostrar" seus imaginários. 
Muito além da importância acadêmica da pesquisa, crianças invisíveis reconstruíram suas histórias e projetaram suas vidas. Seus testemunhos foram expressos em maquetes e fotos. Para elaborar a metodologia de pesquisa, o pesquisador levou em conta que essas crianças se situavam no grupo dos silenciados e que talvez pelas palavras não fosse possível elas expressarem suas vivências muito doloridas. A respeito de outras formas de expressão para falar da dor, Eugénia Vilela (2001, p. 52) comenta:

Pela arte [pelas formas de expressão visual] não se traduz o intraduzível da dor - a dor na terceira pessoa é uma ficção - mas cria-se o espaço de manifestação possível ao toque, através da disseminação do sofrimento vivido por quem o sofreu desde dentro. [...] Dizer as imagens e as palavras - os olhos e as vozes - é a única forma de dar visibilidade à impossibilidade de sentido de certos acontecimentos. Fazê-los furar a pele dos que veem ou leem, como uma luz que atravessa os olhos mesmo com as pálpebras fechadas, no limite da transparência da impossibilidade de olhar.

A metodologia desenvolvida com materiais visuais de Feitosa (2011), assim como das outras pesquisadoras, oportunizou às crianças situações em que elas puderam salientar aspectos que seriam difíceis de ser expressos e "vistos" em uma conversa, entrevista ou texto. Para as crianças, também foram momentos de compartilhar seus saberes sobre as linguagens visuais e produzirem "dados" que rompiam com as lógicas narrativas da linguagem falada. Por outro lado, os materiais visuais produzidos pelas crianças convocaram as pesquisadoras a examiná-los em sua dimensão imagética e não apenas de conteúdo.

\section{"PARA QUE SERVE UM LIVRO SEM FIGURAS?"}

Alice, personagem de Lewis Carrol (2002, p. 2), ao ver o livro da irmã, faz essa pergunta, que agora serve de mote para pensarmos sobre os diferentes papéis que os materiais visuais ocupam nos artefatos acadêmicos. A pergunta que se coloca é: "Para que servem as figuras nos artefatos acadêmicos?"

Nos trabalhos analisados, algumas pesquisadoras (DIEFENTHÄLER, 2009; PETRY, 2009; FERREIRA, 2012; TROIS, 2012) se lançaram em voos ousados realizando experimentações com a linguagem visual como possibilidade discursiva e expressiva no artefato acadêmico, dialogando e/ou ampliando o texto escrito. São ousados porque raramente vemos artefatos acadêmicos na Educação que rompam com os usos tradicionais da imagem em relação ao 
texto. Em geral, as imagens são meras ilustrações dos textos escritos, são imagens-exemplo aprisionadas às palavras.

Além de as imagens exercerem funções que extrapolam a ilustração, muitos trabalhos são apresentados no formato "paisagem" e impressos em papéis com diferentes texturas e gramaturas, alguns deles funcionavam como caixas de surpresas, dando um aspecto lúdico e ao mesmo tempo subtraindo o caráter formal dos trabalhos acadêmicos. Em um deles, o artefato foi apresentado em pequenos cadernos dentro de pequenas caixas, cabendo ao leitor escolher seus percursos de leitura.

Em O privilégio de estar com as crianças: o currículo das infâncias (TROIS, 2012), uma pesquisa fundamentada na observação participante, as imagens fotográficas tiveram um papel tão importante quanto o texto escrito. Desde o início, a autora demarca que as imagens terão função narrativa equivalente ao texto escrito, o que se revela na "lista de figuras" onde aparecem apenas duas "figuras" apesar de o trabalho apresentar centenas de fotografias. Ao não colocar as imagens fotográficas na lista, a autora está anunciando que suas imagens não são ilustrativas, mas estão ali como forma de argumentação e para dialogar com os conceitos. A seguir, no sumário, junto com os títulos das seções, as imagens fotográficas anunciam que, assim como as palavras, elas potencializam as temáticas abordadas. No corpo do artefato, o recurso mais utilizado é a repetição de uma mesma cena a partir da sua decomposição. Tal recurso compositivo intensifica a cena em seus detalhes, fazendo com que a mesma imagem funcione como unidades independentes e ao mesmo tempo como uma narrativa que aponta para detalhes despercebidos na cena inteira. Essas imagens nos convocam a percorrê-las, solicitam nosso olhar nos fragmentos e nos instigam a "reunir" os pedaços de outras maneiras.

As imagens fotográficas de Educação Infantil: vida-história de grupo $e(m)$ processos de criação se desprendem do texto escrito e transformamse no texto principal. Com um estudo mais aprofundado sobre fotografia, a pesquisadora-fotógrafa explorou exaustivamente as possibilidades das imagens. Nas suas imagens-poéticas, o explícito das cenas não é mostrado, mas insinuadas as presenças com o recurso da ausência. É um jogo que oferece um vestígio que poderá desencadear no leitor a criação de outras imagens e narrativas. Algumas vezes a pesquisadora-fotógrafa enquadra o que a criança poderia estar olhando e não o que ela, pesquisadora, vê na criança. Em outros momentos, as imagens nos conduzem para dentro delas, 
e queremos descobrir o que há na ponta do dedo de um menino, ou o que aquele grupo de crianças, de costas para nós, está conversando. Assim como Trois, porém utilizando outros recursos visuais, Petry torna suas imagens convocatórias imagens que nos solicitam a descobrir mais da cena além daquilo que é visibilizado. Petry, ao longo de suas narrativas visuais, prende nossa atenção, nos dá espaço para imaginar, supor, dialogar e, principalmente, nos provoca a criar outras imagens (e conceitos) sobre crianças e suas relações.

Quando a pesquisadora é uma professora-fotógrafa e seu objeto de estudo é a fotografia e o fotografar de seus alunos, em Aluno far foto? O fotografar na escola (especial), a expectativa é que a fotografia seja a principal fonte de imagens no artefato acadêmico. E é, mas Ferreira explora a diagramação e insere elementos gráficos nas fotografias, elaborando composições mesclando os registros das crianças com cenas da pesquisa. De modo similar a uma das propostas metodológicas desenvolvidas na pesquisa, a fotonarrativa, Ferreira recria os acontecimentos da pesquisa e propõe outra forma de visibilizá-la. Segundo a autora: "O 'isto foi', expressão clássica ao referir-se sobre o estatuto da imagem, segundo Barthes, foi substituído pelo 'isto pode ser', marca da constante possibilidade de renovação pelas infinitas formas de composição das imagens" (FERREIRA, 2012, p. 136). Desse modo, a pesquisadora-fotógrafa rompe com o registro "fidedigno", com a ordem dos acontecimentos, com o material visual esparso e produz outra narrativa no artefato acadêmico utilizando vários recursos da linguagem visual. É uma transformação das imagens-registro para imagens poéticas, convocatórias e deslizantes.

As pesquisadoras utilizaram as imagens fotográficas de modo incomum nos artefatos acadêmicos, assim como nas metodologias de pesquisas, cada uma delas deixando sua "marca" conforme suas concepções teóricas, experiências e repertórios visuais. Há recriação dos acontecimentos da pesquisa, as imagens deixam de ser apenas registros em sequência e passam a ser narrativas, "um processo performativo de fazer ou contar uma história”, conforme Martins (2009, p. 38).

\section{DAS EXPERIMENTAC̣ÕES ÀS METODOLOGIAS VISUAIS NA PESQUISA}

Elaborar, criar, engendrar, gerar, manipular, olhar, enxergar, admirar, ver imagens são ações que nos acompanham ao longo de séculos. Desde os registros pré-históricos na caverna de Chauvet Pontd'Arc, os ocidentais mantêm diferentes vínculos com as imagens, por isso somos uma sociedade ocularcêntrica. Atualmente é inegável a 
participação das imagens em nossas vidas, porém, ainda são recentes os estudos no campo da Educação que se preocupam com a cultura visual e as práticas culturais engendradas por ela. É paradoxal nossa relação com as imagens: reconhecermos seu agenciamento, porém, menosprezamos sua retórica nas pesquisas acadêmicas. No entanto, nota-se, nos últimos anos, um esforço dos(as) pesquisadores/as, no que se refere às pesquisas com criança, em buscar outras formas de trabalhar com os materiais visuais, como, por exemplo, as imagens fotográficas abandonarem a função de registro "fidedigno" e de verossimilhança dos acontecimentos da pesquisa e passarem a constituir narrativas interpretativas e argumentativas. Também procuramos modificar o ponto de vista do pesquisador-fotógrafo e enquadrar a fotografia como se fosse o olhar da criança.

$\mathrm{Na}$ primeira década do século XXI surgem no Brasil os primeiros trabalhos acadêmicos na área de Educação Infantil (CUNHA, 2005; DIEFENTHÄLER, 2009; HORN, 2010; ABREU, 2010; NUNES; 2010, entre outros) enfocando a participação dos artefatos visuais nas culturas infantis e ao mesmo tempo modificando os modos de conceber/desenvolver pesquisa com materiais visuais. Experimentos que talvez possam constituir metodologias visuais, onde imagens e palavras possam dialogar e ampliar nossos modos de ver e interpretar o mundo.

No levantamento realizado e analisado neste artigo, se evidencia que as 12 pesquisadoras buscaram uma utilização diferenciada das imagens em vários momentos da pesquisa. Da concepção das investigações, produção dos dados à apresentação no artefato acadêmico, a intenção das pesquisadoras foi encontrar outras formas de produzir e visibilizar as imagens, oportunizando tanto às crianças - sujeitos das pesquisas - quanto aos leitores outras possibilidades de imaginar situações, refletir e relacioná-las a outros contextos. Pode-se afirmar que a concepção que guiou as pesquisadoras, não explicitada e discutida teoricamente no corpo dos trabalhos, parte do pressuposto de que as imagens são plurívocas, cabendo aos leitores realizar múltiplas leituras suscitadas por elas. Imagens poéticas, convocatórias, deslizantes, denominações utilizadas provisoriamente neste levantamento, estendem-se além de seus significantes e recriam outros significados e por que não outros conceitos de criança, infâncias, conhecimentos e culturas infantis?

De um modo geral, na pesquisa educacional, estamos longe de situarmos as produções visuais das crianças como dados tão importantes quanto aqueles expressos pela linguagem verbal, 
também vale ressaltar que são recentes as metodologias de pesquisa com crianças que as posicionam como autoras dos materiais visuais. Em muitas pesquisas aqui analisadas, as crianças pequenas produziram os materiais (dados das pesquisas) como desenhos, fotografias, vídeos, maquetes, bonecos, animações, livros imagéticos, entre outros, como forma de expor seus pontos de vista. Entende-se que não é apenas a substituição da linguagem verbal pela visual, mas outra forma de estabelecer as relações, muitas vezes hierárquicas, de saber entre crianças e pesquisadoras, onde as linguagens visuais - modos corriqueiros de expressão infantil - passam a ter relevância. Ao utilizar materiais visuais como recurso metodológico, pesquisadoras e crianças se confrontam com outras formas de expressão e aprendizagens nos processos investigativos e incentivam pesquisadores/as a romperem com as certezas que a linguagem verbal sempre lhes ofereceu. Várias pesquisadoras, entre elas Müller (2006), Horn (2010) e Ferreira (2012), atribuem, nos decorrer das investigações, às crianças os registros fotográficos e fílmicos. Com isso, as crianças se posicionam como investigadores e não apenas sujeitos da investigação. São seus pontos de vista sobre o mundo, seus enquadramentos, seus critérios, valores estéticos que são expressos.

Por outro lado, a utilização dessas produções visuais infantis nos artefatos pode causar desequilíbrios aos leitores, acostumados com as lógicas adultocêntricas de construção das imagens. Assim, a diversidade das soluções visuais próprias das crianças ou "fora" dos padrões visuais com que estamos acostumados nas pesquisas podem contribuir para sobressaltar, estranhar o olhar dos(as) investigadores / as e os diferentes públicos que acessam as produções acadêmicas.

Tanto os trabalhos acadêmicos aqui mencionados, quanto as análises deste artigo são experimentações exploratórias que estamos empreendendo no contexto acadêmico brasileiro. Cada trabalho é um risco, um desafio, uma vontade de transformar, parcialmente, os modos de fazer pesquisa na contemporaneidade com imagens, com diferentes materiais visuais que não ilustram textos, mas problematizam a visualidade do cotidiano e constroem outros relatos de pesquisa. Pesquisa com crianças significa um recomeçar a cada investigação, uma recomposição de nós, pesquisadoras, nos cotidianos escolares com professoras, diretoras, monitoras, horários, rotinas, exigências administrativas, legais, autorizações em várias esferas e principalmente um recomeço com os grupos de crianças e com cada criança. Para além do "reajuste" a cada entrada em campo, precisamos sempre de olhares atentos para as metodologias e materiais que serão/são elaboradas no próprio desenvolvimento da pesquisa. 
É um trabalho árduo porque requer adequação e recriação constante por parte dos(as) pesquisadores/as. O que é significativo em palavras, frases, expressões, olhares, gestos, silêncios, risos, murmúrios, correrias, empurrões, toques, carinhos, afagos, cheiros, barulhos, deslocamentos, agrupamentos, isolamentos? Como podemos compreender as crianças e depois narrá-las para que outros/ as estudiosos/as possam usufruir nossas investigações?

Investigação junto a crianças significa realizar um trabalho de criptografia, onde há a necessidade de decifrarmos e não interpretarmos aquilo que vai além das evidências explícitas. Procuramos - isso não quer dizer que seja sempre possível - nos descolarmos desta posição de "falar por elas" e entender que a pesquisa com crianças requer outros (re)posicionamentos por parte dos/as pesquisadores/as, tendo em vista que há uma imensa distância entre o que supomos saber sobre as crianças e o que elas pensam, dizem e expressam sobre suas relações com o mundo em suas múltiplas linguagens.

Para superarmos a fase experimental da pesquisa visual com crianças e chegarmos a algumas sistematizações de metodologias visuais, há um longo percurso teórico e vivencial a percorrer com autores/artistas que discutem e fabricam imagens. Para criarmos outras imagens e narrarmos nossas pesquisas, é necessário aprendermos a manipulá-las, problematizá-las e termos intimidade com as diferentes linguagens visuais.

\section{REFERÊNCIAS}

ABREU, Luciane. Bruxas, bruxos, fadas, princesas, príncipes e outros bichos esquisitos...: as apropriações infantis do belo e do feio nas mediações culturais. 2010. 158f. Dissertação (Mestrado em Educação) - Programa de Pós-Graduação em Educação, Faculdade de Educação, Universidade Federal do Rio Grande do Sul, Porto Alegre, 2010.

ACHUTTI, L.E.R. Fotoetnografia da Biblioteca Jardim. Porto Alegre: Editora da UFRGS, 2004. BARTHES, Roland. O óbvio e o obtuso: Ensaio críticos III. Rio de Janeiro: Nova Fronteira, 1990. BRUM, Luciana Hahn. O kañe (olhar) na cidade: práticas de embelezamento corporal na infância feminina Kaingang. 2011, 130f. Dissertação (Mestrado em Educação) - Programa de Pós-Graduação em Educação, Faculdade de Educação, Universidade Federal do Rio Grande do Sul, Porto Alegre, 2011.

CARROL, Lewis. Alice no país das maravilhas. Editorial Arara Azul, Fonte Digital, Versão e-Book, 2002. Disponível em: <http:/ /www.ebooksbrasil.org/eLibris/alicep.html>. Acesso em: 22 mar. 2013.

CASTRO, Lúcia R. Conhecer, transformar(-se) e aprender: pesquisando com crianças e jovens. In: CASTRO, Lúcia Rabello e BESSET, Vera Lopes (Org). Pesquisa-intervenção na infância e juventude. Rio de janeiro: Trarepa/FAPERJ, 2008. 
CUNHA, VIEIRA da Susana R. Entre Van Goghs, Monets e Mônicas: a infância educada através das imagens. Revista Ciências \& Letras, FAPA, Porto Alegre, v. 43, n. 1, p. 107-124, jan/jun. 2005.

Educação e cultura visual: Uma trama entre imagens e infância. 2005. 258f. Tese (Doutorado em Educação) - Programa de Pós-Graduação em Educação, Faculdade de Educação, Universidade Federal do Rio Grande do Sul, Porto Alegre, 2005.

DIAS, Belidson B. Border epistemologies: Looking at Almodóvar's Queer Genders and their implications for Visual Culture Education. Tese. 2006, 325f. (Doutorado em Educação). University Of British Columbia, Vancouver, Canadá, 2006.

Uma epistemologia de fronteira: minha tese de doutorado como um projeto $\mathrm{a} / \mathrm{r} /$ tografico. 2009. Disponível em: <www.anpap.org.br/anais/2009/pdf/ceav/belidson_dias _bezerra_junior.pdf $>$. Acesso em: 15 mar. 2013.

DIEFENTHÄLER, Daniela, R. L. A gente pode fazer casa do jeito que a gente quiser? Ações propositoras e materiais provocadores ampliando o imaginário infantil. 2009, 184f. Dissertação (Mestrado em Educação) - Programa de Pós-Graduação em Educação, Faculdade de Educação, Universidade Federal do Rio Grande do Sul, Porto Alegre, 2009.

EISNER, Elliot. El ojo ilustrado. Barcelona: Paidós Ibérica SA, 1998.

FEITOSA, Antonio G. da Silva. A infância abrigada: Impressões das crianças na casa abrigo. 2011, 159f. Dissertação (Mestrado em Educação) - Programa de Pós-Graduação em Educação, Faculdade de Educação, Universidade Federal do Rio Grande do Sul, Porto Alegre, 2011

FERREIRA. Anelise B. O aluno faz foto? o fotografar na escola (especial). 2012, 168f. Tese (Doutorado em Educação), Faculdade de Educação/Programa de Pós-Graduação em Educação, UFRGS, Porto Alegre, 2012.

FISCHMAN, Gustavo. Las fotos escolares como analizadoras em la investigación educativa. Revista Educação e Realidade, UFRGS, Porto Alegre, v. 31, n. 2, p. 79-94, jul/dez 2006.

GUIMARÃES, Rosele. Encontros, cantigas, brincadeiras, leituras: Um estudo acerca da interação dos bebês e as crianças bem pequenas com o objeto livro numa turma de berçário. 2011, 226f, Dissertação (Mestrado em Educação) - Programa de Pós-Graduação em Educação, Faculdade de Educação, Universidade Federal do Rio Grande do Sul, Porto Alegre, 2011.

HANSEN, Paul. Homens carregando crianças palestinas mortas. Jornal eletrônico globo. com. Rede Globo, 15 de fevereiro de 2013. Disponível em: <http://g1.globo.com/poparte/noticia/2013/02/fotografo-sueco-paul-hansen-ganha-world-press-photo.html>. Acesso em: 17 fev. 2013.

HERNÁNDEZ, Fernando. Catadores da Cultura Visual: uma proposta para uma nova narrativa educacional. Trad. de Ana Duarte. Editora Mediação, Porto Alegre: 2007.

HERNÁNDEZ, Fernando. La investigación basada en las artes: propuestas para repensar la investigación en educación. 2008. Disponível em: <www.doredin.mec.es/documentos/0 1820083002551.pdf>. Acesso em: 20 fev. 2013.

HORN, Ticiana E. Pés descalços e tênis, carroça e carro, boneca de pano e computador, entre o rural e o urbano: experiências num entrecruzar de infâncias. 2010, 133f. Dissertação (Mestrado em Educação) - Programa de Pós-Graduação em Educação, Faculdade de Educação, Universidade Federal do Rio Grande do Sul, Porto Alegre, 2010.

IRWIN, Rita. A/r/tografia: uma mestiçagem metonímica. In BARBOSA, Ana Mãe e AMARAL, Lilian.(orgs). Interterritorialidade: mídias, contextos e educação. São Paulo: Editora SENAC SP; Edições SESC SP, 2008, p. 87-104. 
JARDIM, João. Pro dia nascer feliz: Documentário, Brasil: 2005.

JOBIM e SOUZA, Solange. LOPES, Ana Elisabete. Fotografar e narrar: a produção do conhecimento no contexto da escola. Cadernos de Pesquisa, n. 116, julho/ 2002. p. 61-80 Disponível em: < http://www.scielo.br/pdf/cp/n116/14399.pdf>. Acesso em: 3 mar. 2013.

MARTINS, Raimundo. Narrativas visuais: imagens, visualidades e experiência educativa. In: Vis. Revista do Programa de Pós-graduação em Arte. Brasília, janeiro/junho de 2009, v. 8, n. 1, p. 33-39.

MIRZOEFF, Nicholas. Una introducción a la cultura visual. Trad. Paula Garcia Segura. Barcelona: Editorial Paidós Ibérica, 2003.

MÜLLER, Fernanda. Retratos da infância na cidade de Porto Alegre. 2007, 217f. Tese. (Doutorado em Educação), Programa de Pós-Graduação em Educação, Faculdade de Educação, Universidade Federal do Rio Grande do Sul, Porto Alegre: 2007.

NUNES, Luciana B. As imagens que invadem as salas de aula: Reflexões sobre cultura visual. Curitiba: IDÉIAS \& LETRAS, 2010.

PEREIRA, Rachel F. IK. 2011, 207f. Dissertação (Mestrado em Educação) - Programa de Pós-Graduação em Educação, Faculdade de Educação, Universidade Federal do Rio Grande do Sul, Porto Alegre, 2011.

PEREIRA, Rita Ribes. Reflexões sobre a feitura e os usos da imagem na pesquisa em educação: os óculos de Win Wenders e o olhar de Bavcar. ETD - Educação Temática Digital, Campinas, v. 11, n., jul./dez. 2009. p. 255-272. Disponível em: <http://www.fae.unica mp.br/revista/index.php/etd/article/view/2019>. Acesso em: 10 mar. 2013.

PETRY, Letícia. Educação infantil: vida-história de grupo e(m) processos de criação. 2009, 252f. Dissertação (Mestrado em Educação) - Programa de Pós-Graduação em Educação, Faculdade de Educação, Universidade Federal do Rio Grande do Sul: 2009.

RAMOS, Anne Carolina. Meus avós e eu: as relações intergeracionais entre avós e netos na perspectiva das crianças. 2011, 464f. Tese. (Doutorado em Educação) Programa de PósGraduação em Educação, Faculdade de Educação, Universidade Federal do Rio Grande do Sul, Porto Alegre, 2011.

RANCIÈRE, Jaques. O destino das imagens. Rio de Janeiro: Contraponto, 2012.

ROSE, Gillian. Visual methodologies: An introduction to the interpretation of visual materials. London: SAGE Publications, 2001.

SARMENTO, Manuel Jacinto. Culturas infantis e interculturalidade. In: DORNELLES, Leni Vieira (org). Produzindo Pedagogias Interculturais na Infância. Petrópolis: Vozes, 2007. p. $19-40$.

SONTAG, Susan. Ao mesmo tempo. Ensaios e Discursos. São Paulo: Companhia das Letras, 2008.

SOUZA, Fernanda M. Revirando as Malas: entre histórias de bonecas e crianças. 2008, 134f. Dissertação (Mestrado em Educação) - Programa de Pós-Graduação em Educação, Faculdade de Educação, Universidade Federal do Rio Grande do Sul, Porto Alegre, 2008.

TROIS, Loide. O privilégio de estar com as crianças: o currículo das infâncias. 2012, 183f. Tese (Doutorado em Educação) Programa de Pós-Graduação em Educação, Faculdade de Educação, Universidade Federal do Rio Grande do Sul, Porto Alegre: 2012.

VILELA, Eugènia. Corpos inabitáveis: errância, filosofia e memória. In LARROSA, Jorge. e SKLIAR, Carlos. (orgs). Habitantes de Babel: políticas e poéticas da diferença. Belo Horizonte: Autêntica, 2001. p. 233-254. 
VIRILIO, Paul. A máquina de visão. 2a . Edição, Rio de Janeiro: José Olympo, 2002.

WOLFF, Francis. Por trás do espetáculo: O poder das imagens. In: NOVAES, Adauto (Org.) Muito além do espetáculo. São Paulo: Editora Senac, 2005. p. 16-45.

\section{NOTAS}

${ }^{1} \mathrm{O}$ ensino de arte no Brasil, da educação infantil à universidade, miscigenado de concepções e tendências pedagógicas, nem sempre tem privilegiado a produção imagética, e nas outras áreas do conhecimento são raras as iniciativas que propõem desenvolver processos de constituição da linguagem visual.

${ }^{2}$ Ver: http://www.bjp-online.com/IMG/818/248818/paul-hansen-web.jpg?1360922708. A fotografia ganhou o prêmio "Imagem do ano" no World Press Photo 2012, em Amsterdã.

${ }^{3}$ Pesquisas desenvolvidas em programas de pós-graduação em Educação.

${ }^{4}$ Pesquisas que envolvam educação em qualquer campo de conhecimento.

${ }^{5}$ Martins Filho (2010) constatou, em sua pesquisa baseada nas investigações com crianças apresentados ao longo de dez anos no GT7 da Anped, que o registro fotográfico aparece em 18 dos 25 trabalhos analisados.

${ }^{6}$ Denominação do menu do Word quando se utiliza o sentido horizontal da folha.

Recebido: 23/10/2013

Aprovado: 25/08/2014

Contato:

Universidade Federal do Rio Grande do Sul Faculdade de Educação Departamento de Estudos Especializados Paulo da Gama, s/n Farroupilha Porto Alegre |RS | Brasil CEP 90.010-000 
